\title{
Novel Manganese (II) Acetate Complex for Nitrite Anion
}

\author{
Seema Sharma ${ }^{1}$ and K K Sharma ${ }^{2}$ \\ ${ }^{1}$ Assistant Director of Education, Department of Education, East Delhi Municipal Corporation, ${ }^{2}$ DGM NTPC \\ INDIA
}

\begin{abstract}
A novel potentiometric membrane sensor has been developed and optimized based on 3,5,13,15tetramethyl-4,14-diethyl-2,6,12,16,21,22-hexaazatricyclo $\quad\left[15.3 . \quad I_{1-17} I^{7-11}\right] \quad$ dicosa1,(21),2,5,7,19,11(22),12,15,17,19-decaene Manganese acetate ionophore in poly vinyl chloride matrix membrane (PVC) plasticized with o-nitrophenyloctyl ether (NPOE) for high selective determination of nitrite ion. The sensor works well in a linear range: $1.0 \times 10^{-6}-1.0 \times 10^{-1} \mathrm{M}$ with a Nernstian slope of $-59.8 \pm 0.1$ $\mathrm{mV} /$ decade and its detection limit is $5.0 \times 10^{-7} \mathrm{M}$. The sensor shows working range over the $\mathrm{pH}$ 2.0-9.5 and is stable for a period of 3 months with response time $<10 \mathrm{~s}$. The selectivity coefficient values as determined by fixed interference method indicate a good selectivity for ions over a wide variety of other tested anions.
\end{abstract}

Keywords: Sensor, Ion Selective Electrode, PVC, Potentiometry.

\section{Introduction}

Interest in sensors with enhanced selectivity for nitrite has increased recently owing the discovery of the endogenous enzyme nitric oxide synthase (NOS) which catalyzes the oxidation of arginine to nitric oxide and citrulline in a variety of human cells. The liberated NO reacts rapidly with water and oxygen to generate nitrite and nitrate ions [1-2].

Nitrite is present ubiquitously in soils, waters, foods and physiological systems and has been reported as a human health-hazard. The excess uptake of nitrite would cause gastric cancer [3] and blue body [4]. Therefore, it is necessary to develop a reliable and sensitive sensor to detect nitrite in food, drinking water and environmental samples.

In recent decade some electrochemically modified electrodes of nitrite have been explored to lower the operating potentials for nitrite oxidation [5].

In this work, we describe $[\mathbf{M n L}](\mathbf{a c})_{2}$ [Figure 1] as a novel ionophore used in PVC polymeric nitrite selective electrode.

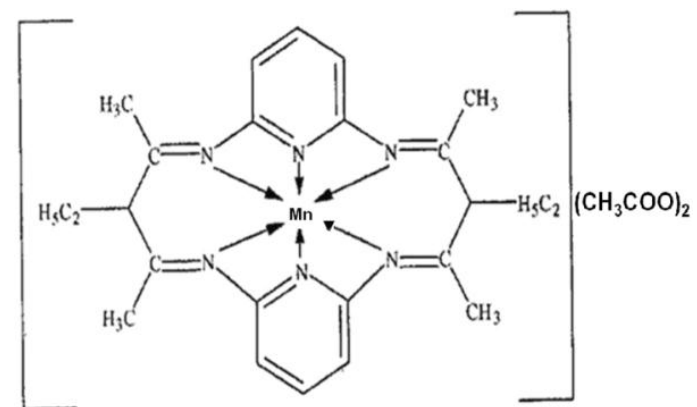

Figure 1 Ionophore $[\mathrm{MnL}](\mathbf{a c})_{2}$

\subsection{Reagents and Instruments}

\section{Experimental}

PVC of high relative molecular weight, hexadecyltri-methylammonium chloride (HTAC), dibutyl phthalate (DBP), Tri-n-butylphosphate(TBP), o-nitrophenyloctyl ether (NPOE), n-butylacetate(BA), and metallic salts used were of the highest purity available from Merck and were used without further purification except for vacuum drying over $\mathrm{P}_{4} \mathrm{O}_{10}$. THF was used as received. All aqueous solutions were prepared with deionized, distilled water. Solution of anionic interferences, for selectivity studies, were prepared mostly from sodium salts in the water. Working solutions were prepared by successive dilutions with water. Potentials were measured with digital potentiometer EQ-602 Equiptronics (accuracy, $0.001 \mathrm{~V}$, India). The pH measurements were carried out on digital $\mathrm{pH}$ meter (LabIndia $\mathrm{pH}$ Conmeter, India). Auto ranging Conductivity meter/TDS meter TCM-15 (Toshniwal Instruments Mfg. Pvt. Ltd Ajmer). 


\subsection{Electrode preparation}

Different compositions of membrane ingredients, including ionophore, the plasticizers NPOE, DBP, BA, TBP, the additive HTAC and PVC as shown in Table 1 were thoroughly dissolved in $10 \mathrm{ml}$ THF. The resulting solution was carefully cast in to a glass dish of $2 \mathrm{~cm}$ diameter for slow evaporation at room temperature to obtain membrane of about $0.3 \mathrm{~mm}$ thickness with optimum composition and behavior. The membrane was cut and pasted to the one end of pyrex tube with the help of araldite. The electrode was then filled with an internal solution of $1.0 \times 10^{-2} \mathrm{M}$ nitrite. The prepared electrodes were finally conditioned by soaking in a $1.0 \times 10^{-2} \mathrm{M}$ nitrite solution for $24 \mathrm{~h}$.

\subsection{EMF Measurements}

EMF measurements with the polymeric membrane were carried out with the following cell assemblies:

$\mathrm{Ag}-\mathrm{AgCl} \mid$ internal solution, $1.0 \times 10^{-2} \mathrm{M} \mathrm{NaNO}_{2} \mid \mathrm{PVC}$ membrane

| test solution $\left|\mathrm{Hg}-\mathrm{Hg}_{2} \mathrm{Cl}_{2}\right| \mathrm{KCl}$ (satd).

The activities were calculated according to the Debye-Huckel procedure [6].

\subsection{Potential response}

\section{Results and Discussion}

In preliminary experiments, the ionophore $[\mathrm{MnL}](\mathrm{ac})_{2}$ was applied in the construction of a number of membrane sensors for different anions. The potential responses for different anionic species are shown in [Figure 2]. As it is seen except for the $\mathrm{NO}_{2}{ }^{-}$ion-selective electrode the slope of the corresponding potential $\mathrm{pA}^{\mathrm{n}-}$ plots is much lower than the expected Nernstian slope and the plots suffer from a limited linear range. However, the nitrite ion resulted in a Nernstian response over a wide concentration range $\left(1.0 \times 10^{-6}-1.0 \times 10^{-1} \mathrm{M}\right)$. This is, most probably, due to both the selective behaviour of the ionophore against $\mathrm{NO}_{2}{ }^{-}$in comparison to other anions tested and the rapid exchange kinetics of the anion, between the aqueous and membrane phases.

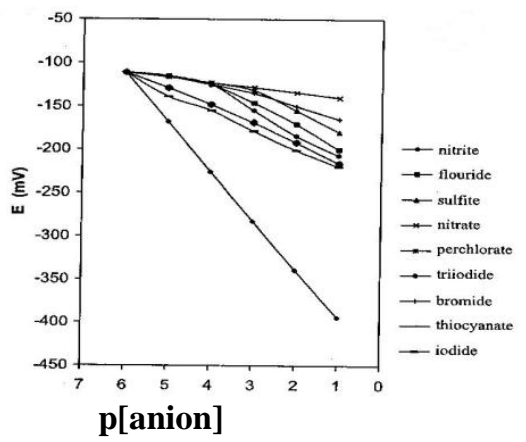

Figure 2 Potential response of various membrane sensors based on $[\mathrm{MnL}](\mathrm{ac})_{2}$

\subsection{UV-Vis. spectra}

To obtain a clue about the interaction mechanism of $[\mathrm{MnL}](\mathrm{ac})_{2}$ with nitrite, the UV-Vis. spectra of $1.0 \times 10^{-4} \mathrm{~mol} \mathrm{~L}^{-1}[\mathrm{MnL}](\mathrm{ac})_{2}$ in DMSO were obtained without and with the presence of $1.0 \times 10^{-4} \mathrm{~mol} \mathrm{~L}^{-1}$ nitrite and the results are shown in [Figure 3]. The decrease in the absorbance of the Soret band at $475 \mathrm{~nm}$, accompanying an $8 \mathrm{~nm}$ red shift after the contact of $[\mathrm{MnL}](\mathrm{ac})_{2}$ with nitrite ion, indicated that there is a specific interaction between the $\mathrm{NO}_{2}{ }^{-}$and $\mathrm{Mn}(\mathrm{II})$ of the studied ionophore.

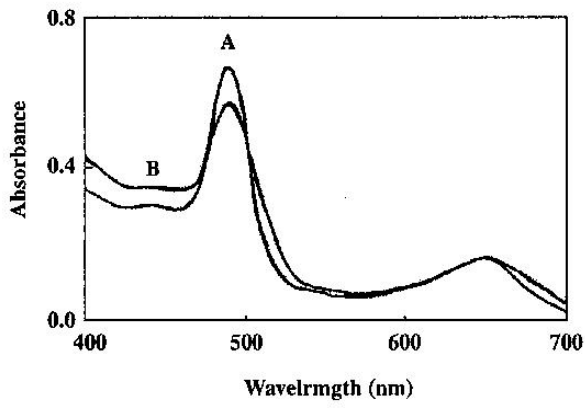

Figure 3 UV-Vis absorption spectra of $[\mathrm{MnL}](\mathrm{ac})_{2}$ in DMSO solution (A)without and (B) with $1.0 \times 10^{-4} \mathrm{M}$ $\mathrm{NO}_{2}^{-}$ 


\subsection{Effect of Plasticizer}

As shown in [Figure 4], among the four solvent mediators used, o-NPOE shows best results than dibutyl phthalate, TBP or benzyl acetate in preparing the nitrite sensor.

The values obtained for correlation coefficients evidenced the good linearity of the calibration curves for each plasticizer used as solvent mediator in this study.

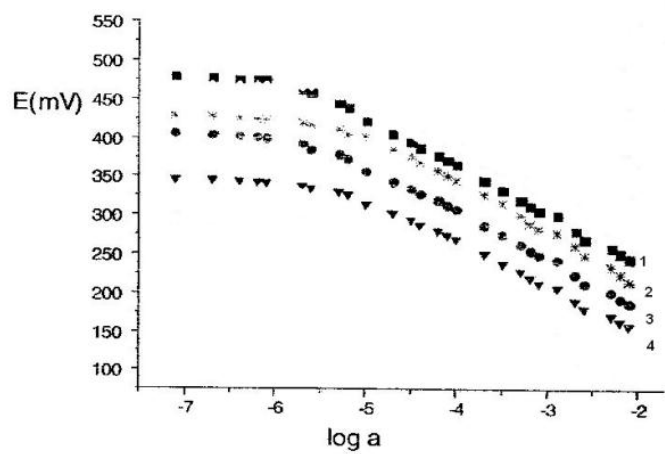

Figure 4 Calibration curves obtained by using different plasticizers as solvent mediators. (1) o-NPOE (2) BA (3) DBP (4) TBP.

\subsection{Optimization of membrane ingredients}

Apart from the critical role the nature of the ion carrier has in preparing membrane-selective sensors some other important features of the PVC membrane, such as the amount of ionophore, the nature of the solvent mediator, the plasticizer/PVC ratio, and especially the nature of additives used, are known to significantly influence the sensitivity and selectivity of the membranes [7-14].

The membrane composition based on ionophore $[\mathrm{MnL}](\mathrm{ac})_{2}$ for nitrite ion-selective sensors were optimized, and the results are given in Table 1. As is obvious from

Table 1, among four solvent mediators used, o-NPOE is a more effective solvent mediator than dibutyl phthalate, TBP or benzyl acetate in preparing the nitrite sensor. It should be noted that the nature of the plasticizer influences both the dielectric constant of the membrane and the mobility of the ionophore and its complex.

The sensitivity of the electrode's response increases with increasing ionophore $[\mathrm{MnL}](\mathrm{ac})_{2}$ content until a value of $2 \%$ is reached. Further addition of ionophore however, resulted in diminished response of the electrode, most probably due to some inhomogenieties and possible saturation of the membrane [15].

Table 1. Optimization of membrane ingredients.

\begin{tabular}{clllccc}
\hline \multicolumn{7}{c}{ Composition \% } \\
\hline No. & PVC & Plasticizer & I & HTAC & Slope & Linear range \\
\hline 1 & 33 & NPOE, 67 & - & 0 & $-5.3 \pm 0.2$ & $1.0 \times 10^{-4}-1.0 \times 10^{-2}$ \\
2 & 33 & NPOE, 65 & 2 & 0 & $-14.3 \pm 0.1$ & $1.0 \times 10^{-4}-1.0 \times 10^{-2}$ \\
3 & 33 & NPOE, 64 & 3 & 0 & $-30.9 \pm 0.3$ & $1.0 \times 10^{-5}-1.0 \times 10^{-2}$ \\
4 & 33 & NPOE, 62 & 4 & 1 & $-51.1 \pm 0.1$ & $1.0 \times 10^{-6}-1.0 \times 10^{-2}$ \\
5 & 33 & NPOE, 61 & 5 & 1 & $-47.9 \pm 0.2$ & $1.0 \times 10^{-6}-1.0 \times 10^{-1}$ \\
6 & 33 & NPOE, 60 & 5 & 2 & $-59.8 \pm 0.1$ & $1.0 \times 10^{-6}-1.0 \times 10^{-1}$ \\
7 & 33 & DBP, 60 & 5 & 2 & $-55.2 \pm 0.2$ & $1.0 \times 10^{-5}-1.0 \times 10^{-1}$ \\
8 & 33 & BA, 60 60 & 5 & 2 & $-52.2 \pm 0.2$ & $1.0 \times 10^{-5}-1.0 \times 10^{-1}$ \\
\hline
\end{tabular}

The data given in Table 1 reveals that the presence of an additive has a beneficial effect on the performance characteristics of the membrane electrode. Addition of $2 \%$ hexamethytrimethylammonium chloride (HTAC) as a suitable additive [16-19] increased the slope of the potential sensor response from a sub-Nernstian value of $-51.1 \mathrm{mV} / \mathrm{decade}$ (No. 4) to a Nernstian value of $-59.8 \mathrm{mV} / \mathrm{decade}$ (No. 6). The presence of cationic additives, such as HTAC, can reduce ohmic resistance and improve the response behavior and selectivity of the membrane electrodes. Moreover, the additives may catalyze the exchange kinetics at the sample-membrane interface.

As is seen from Table 1, the membrane obtained with the PVC:NPOE:I:HTAB percent ratio of 33:60:5:2 shows a Nernstian slope of $-59.8 \pm 0.1 \mathrm{mV}$ per decade over a wide nitrite concentration range. 


\subsection{Effect of the internal solution}

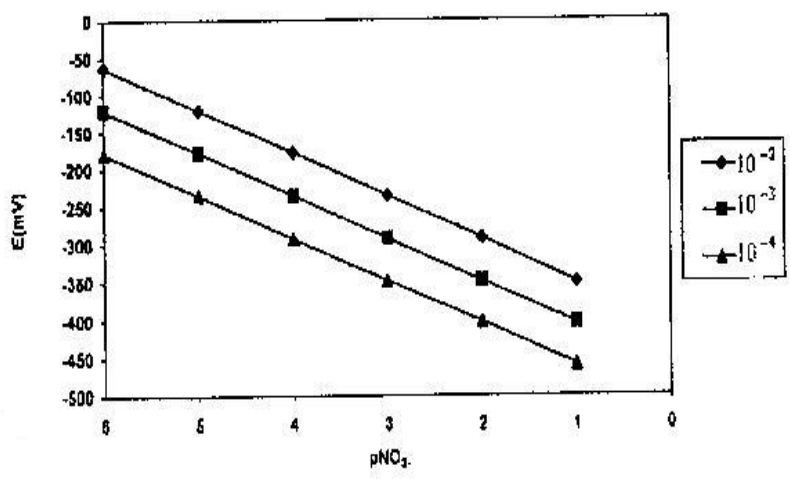

Figure 5 Effect of the internal solution on the potential response of $\mathrm{NO}_{2}^{-}$

The effect of the internal solution concentration on the potential response of the sensor was investigated [Figure 5]. The sodium nitrite concentration was changed from $1.0 \times 10^{-4}$ to $1.0 \times 10^{-2} \mathrm{M}$, and corresponding EMF versus $\mathrm{pNO}_{2}^{-}$plots were obtained. It was found that the concentration of the internal solution has a negligible effect on the potential response of the electrode, except for an expected shift in the intercept of the resulting plots. A $1.0 \times 10^{-3} \mathrm{M}$ concentration of the filling solution was used for further studies.

\subsection{Limit of detection}

The plot of EMF vs. $\mathrm{pNO}_{2}^{-}$obtained with optimal membrane ingredients for the sensor [Figure 6] indicate its Nernstian behavior over wide concentration ranges of nitrite ion. The slope and linear range of the resulting calibration graph are $-59.8 \mathrm{mV}$ per decade and $1.0 \times 10^{-6}-1.0 \times 10^{-1} \mathrm{M}$, respectively. The limit of detection (LOD), defined as the concentration of nitrite ion obtained when the linear regions of the calibration graph are extrapolated to the base line potential, is $5.0 \times 10^{-7} \mathrm{M}\left(\sim 40 \mathrm{mg} \mathrm{mL}^{-1}\right)$.

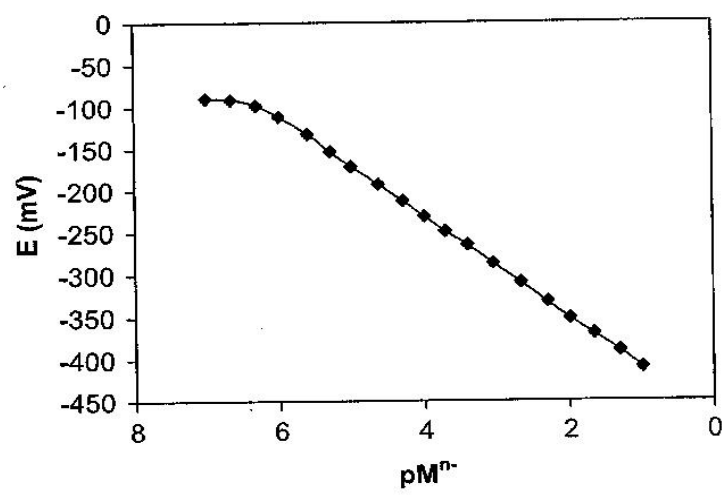

Figure 6 Calibration curve of nitrite electrode.

\subsection{Effect of the pH}

The potential response of the sensor based on $[\mathrm{MnL}](\mathrm{ac})_{2}$ was found to be sensitive to $\mathrm{pH}$ changes. Thus, the $\mathrm{pH}$ dependence of the electrode was tested by measuring the potential response of a solution of varying $\mathrm{pH}$ over a range of 2.0 to 12.0 in the presence of $1.0 \times 10^{-3} \mathrm{M}$ of $\mathrm{NaNO}_{2}$. The $\mathrm{pH}$ adjustments were carried out by nitric acid and sodium hydroxide solution. The sample potential $\mathrm{pH}$ plot for the sensor is shown in [Figure 7]. The results show that the sensor is suitable for nitrite determination in wide pH range of 2.0-9.5. However, the increased potential of the electrode at $\mathrm{pH}>9.5$ can be explained in terms of the increased interference from $\mathrm{OH}^{-}$ions which may have a strong competing ligation reaction with $\mathrm{NO}_{2}{ }^{-}$ions for the central $\mathrm{Mn}(\mathrm{II})$ ion. At higher acidic media $(\mathrm{pH}<2.0)$, the drift in the potential may be due to the instability of the ionophore. 


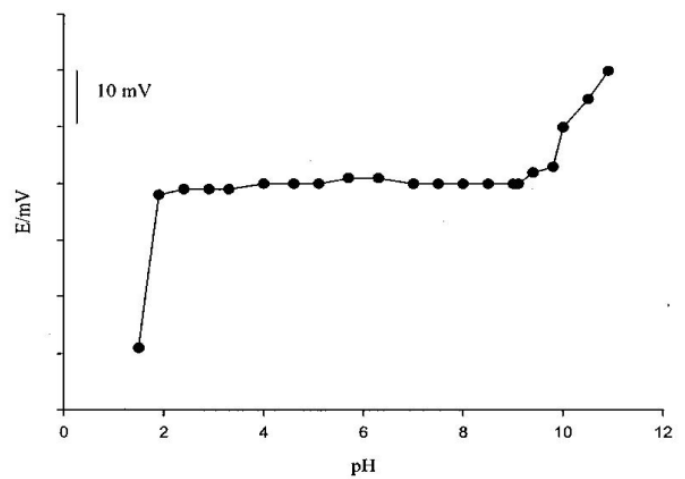

Figure 7 Effect of the $\mathrm{pH}$ of the test solutions on the potential response of the electrode.

\subsection{Optimum equilibration time}

The optimum equilibration times for the membrane sensor in the presence of $1.0 \times 10^{-3} \mathrm{M}$ sodium nitrite were investigated and found to be $24 \mathrm{~h}$, after which the electrode generated stable potentials in contact with nitrite ion solutions. The standard deviation of 10 replicate potential measurements for the proposed electrode was at the most $\pm 0.4 \mathrm{mV}$. The proposed electrode was very stable and could be used for at least 2 months without observing any change in response characteristics.

\subsection{Dynamic response time}

The dynamic response time is an important factor in any ion-selective electrode. In this study, the practical response time was recorded by changing the nitrite concentration in the solution over a concentration range of $1 \times 10^{-1}$ to $1.0 \times 10^{-6} \mathrm{M}$. The results are shown in [Figure 8]. As seen over the entire concentration range, the electrode reaches its equilibrium response in a very short time $(<10 \mathrm{~s})$. This is most probably due to the fast exchange kinetics of the complexation-decomplexation of nitrite ions with the $[\mathrm{MnL}](\mathrm{ac})_{2}$ at the test solutionmembrane interface.

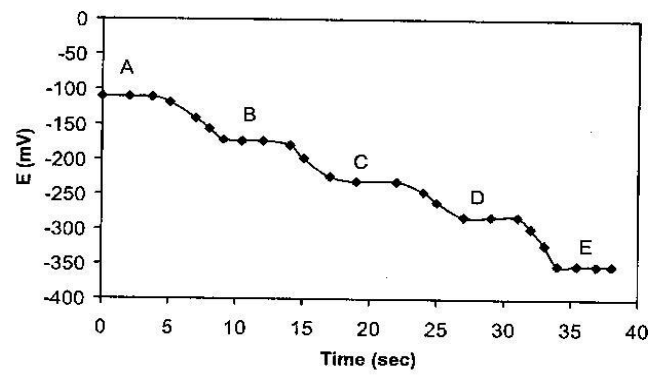

Figure 8 Dynamic response time of the nitrite electrode for step changes in concentration of $\mathrm{NO}_{2}^{-}(\mathrm{A})$

$$
1.0 \times 10^{-6} \mathrm{M},(\mathrm{B}) 1.0 \times 10^{-5} \mathrm{M},(\mathrm{C}) 1.0 \times 10^{-4} \mathrm{M},(\mathrm{D}) 1.0 \times 10^{-3} \mathrm{M}, \text { (E) } 1.0 \times 10^{-2} \mathrm{M}, 3.10 \quad \text { Life-Time }
$$

The long-term stability of the electrode was studied by periodically recalibrating in standard solutions and calculating the response slope over the range of $1.0 \times 10^{-6}$ to $1.0 \times 10^{-1} \mathrm{M}[\mathbf{2 0}, \mathbf{2 1}]$. The slopes of the electrode response were reproducible to within $2.0-3.0 \mathrm{mV}$ per decade over a period of 3 months and the results are given in Table 2.

Table 2 Stability and reproducibility of the nitrite-selective electrode $(n=5)$

\begin{tabular}{llc}
\hline Time (day) & Slope $(\mathrm{mV}$ per decade $)$ & Linear range $(\mathrm{M})$ \\
\hline 1 & $-\mathbf{5 9 . 8} \pm 0.4$ & $1.0 \times 10^{-6}$ to $1.0 \times 10^{-1}$ \\
7 & $-59.8 \pm 0.4$ & $1.0 \times 10^{-6}$ to $1.0 \times 10^{-1}$ \\
14 & $-59.8 \pm 0.4$ & $1.0 \times 10^{-6}$ to $1.0 \times 10^{-1}$ \\
21 & $-59.0 \pm 1.0$ & $1.0 \times 10^{-6}$ to $1.0 \times 10^{-1}$ \\
35 & $-58.5 \pm 1.0$ & $1.0 \times 10^{-6}$ to $1.0 \times 10^{-1}$ \\
49 & $-58.5 \pm 1.0$ & $1.0 \times 10^{-6}$ to $1.0 \times 10^{-1}$ \\
60 & $-58.0 \pm 1.5$ & $1.0 \times 10^{-6}$ to $1 \times 10^{-1}$ \\
70 & $-57.5 \pm 1.5$ & $1.0 \times 10^{-6}$ to $1 \times 10^{-1}$ \\
90 & $-57.0 \pm 1.5$ & $1.0 \times 10^{-6}$ to $1 \times 10^{-1}$ \\
\hline
\end{tabular}


Table 3. Characteristics of optimized nitrite-ISE

\begin{tabular}{ll}
\hline Linear range $/ M$ & $1.0 \times 10^{-6} \mathbf{M}-\mathbf{1 . 0} \times 10^{-1} \mathrm{M}$ \\
Slope $/ \mathbf{m V d e c a d e}$ & $-\mathbf{5 9 . 8} \pm \mathbf{0 . 1} \mathrm{mV} \mathrm{decade}^{-1}$ \\
pH range & $\mathbf{2 . 0 - 9 . 5}$ \\
Detection limit $/ \mathbf{M}$ & $\mathbf{5 . 0} \times \mathbf{1 0} \mathbf{m o l}^{-7} \mathrm{~mol}^{-1}$ \\
Life time/month & $>\mathbf{3}$ \\
Response time $/ \mathrm{s}$ & $<\mathbf{1 0 s}$
\end{tabular}

\subsection{Selectivity of the electrode}

Potentiometric selectivity coefficient, defines the ability of an ion-selective electrode to distinguish between different ions in the same solution. It is not identical to the similar term used in separation process. The selectivity coefficient should preferably be evaluated by measuring the response of an ion selective electrode in solutions of the primary ion, $\mathrm{NO}_{2}^{-}$, and interfering ion, $\mathrm{A}^{-}$(fixed interference method). The selectivity

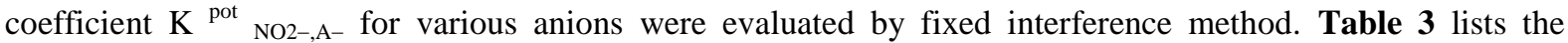
potentiometric selectivity coefficient data of the sensor for several anions relative to nitrite. The selectivity coefficients clearly indicate that the electrode selective to nitrite over a number of other inorganic and organic anions. In this work, interference studies were made for $\mathrm{F}^{-}, \mathrm{Cl}^{-}, \mathrm{Br}^{-}, \mathrm{I}^{-}, \mathrm{CH}_{3} \mathrm{COO}^{-}, \mathrm{SCN}^{-}, \mathrm{CN}^{-}$and $\mathrm{IO}_{3}^{-}$ monovalent ions.

The reason that these ions were chosen in determining the selectivity coefficient was that they are generally present in the media when nitrate is present (in drinking water, fertilizers, etc.).

As can be seen from Table 4, the most interfering anion to the electrode is $\mathrm{I}^{-}$and salicylate. Table 4 indicates that the selectivity coefficients of the nitrite-selective electrode prepared in this study against ions such as $\mathrm{F}^{-}$, $\mathrm{Cl}^{-}, \mathrm{Br}^{-}, \mathrm{I}^{-}$and $\mathrm{OAc}^{-}$are approximately better than as those that are commercially available (with comparison the tabulated data in Table 4). The interfering effect of the ions is in the following order:

$$
\mathrm{I}^{-}>\mathrm{SCN}^{-}>\mathrm{Br}^{-}>\mathrm{CH}_{3} \mathrm{COO}^{-}>\mathrm{F}^{-}>\mathrm{Cl}^{-}
$$

The reason that the selectivity coefficients of this electrode do not comply with the Hofmeister series, and show an anti-Hofmeister behavior, is thought to be due to the possible interaction of the anions with $\mathrm{Mn}(\mathrm{III})$.

Table 4 Selectivity of coefficients, determined by use of the fixed interference method for the nitriteselective electrode

\begin{tabular}{|c|c|c|c|c|c|}
\hline Interfering ion & $\log \mathrm{K}^{\mathrm{pot}}{ }_{\text {nitrite }} \mathrm{A}-$ & Interfering ion & $\log \mathrm{K}^{\mathrm{pot}}{ }_{\text {nitrite, }} \mathrm{A}^{-}$ & & \\
\hline$\overline{F^{-}}$ & -3.5 & & $\mathrm{CO}_{3}{ }^{2-}$ & -3.5 & \\
\hline $\mathrm{Cl}^{-}$ & -3.6 & & Citrate & -2.8 & \\
\hline $\mathrm{Br}^{-}$ & -1.8 & & $\mathrm{IO}_{3}^{-}$ & & -3.3 \\
\hline $\mathbf{I}^{-}$ & -1.2 & & $\mathrm{SO}_{4}{ }^{2-}$ & & -2.9 \\
\hline SCN- & -1.3 & & $\mathrm{PO}_{4}{ }^{3-}$ & -2.9 & \\
\hline $\mathrm{OAc}^{-}$ & -3.0 & & $\mathrm{C}_{2} \mathrm{O}_{4}{ }^{2-}$ & -2.9 & \\
\hline Salicylate & -1.0 & & $\mathrm{HPO}_{4}{ }^{2-}$ & -2.6 & \\
\hline
\end{tabular}

\subsection{Effect of non-aqueous media on the electrode response.}

The performance of the proposed sensors was investigated in partially non-aqueous media using methanol, ethanol and acetone mixtures with water. The calibration plot of the electrode was obtained in the different mixture (v/v) of methanol-water, ethanol-water and acetone-water. From the data obtained in Table 5, it was found that the membrane electrode did not show any appreciable change in working concentration range and slope in mixtures up to $20 \%(\mathrm{v} / \mathrm{v})$ nonaqueous contents. However above $20 \%(\mathrm{v} / \mathrm{v})$ nonaqueous content, potentials show drift with time. The drift in potentials in the organic phase is probably due to leaching of the ionophore at higher organic content. 
Table 5 Effect of partially non-aqueous media on the response of $[\mathrm{MnL}](\mathrm{ac})_{2}$ nitrite selective polymeric membrane electrode.

\begin{tabular}{|c|c|c|}
\hline $\begin{array}{l}\text { Non-aqueous } \\
\text { Content }(\% \mathrm{v} / \mathrm{v})\end{array}$ & $\begin{array}{c}\text { Slope } \\
(\mathrm{mV} / \text { decade })\end{array}$ & Linear range $\left(\mathrm{mol} \mathrm{L}^{-1}\right)$ \\
\hline 0 & 59.8 & $1.0 \times 10^{-6}-1.0 \times 10^{-1}$ \\
\hline \multicolumn{3}{|l|}{ Methanol } \\
\hline 10 & 59.8 & $1.0 \times 10^{-6}-1.0 \times 10^{-1}$ \\
\hline 20 & 59.6 & $1.0 \times 10^{-6}-1.0 \times 10^{-1}$ \\
\hline 30 & 46.5 & $1.5 \times 10^{-5}-1.0 \times 10^{-1}$ \\
\hline \multicolumn{3}{|l|}{ Ethanol } \\
\hline 10 & 59.8 & $1.0 \times 10^{-6}-1.0 \times 10^{-1}$ \\
\hline 20 & 59.3 & $1.0 \times 10^{-6}-1.0 \times 10^{-1}$ \\
\hline 30 & 45.8 & $2.0 \times 10^{-5}-1.5 \times 10^{-1}$ \\
\hline \multicolumn{3}{|l|}{ Acetone } \\
\hline 10 & 59.8 & $1.0 \times 10^{-6}-1.0 \times 10^{-1}$ \\
\hline 20 & 59.0 & $1.0 \times 10^{-6}-1.0 \times 10^{-1}$ \\
\hline 30 & 45.2 & $7.2 \times 10^{-5}-1.0 \times 10^{-1}$ \\
\hline
\end{tabular}

\section{Analytical Applications}

Nitrites are widely used in the production and preservation of cured meat products, but are well known as toxic substances. The major effect of nitrites is the induction of methaemoglobinemia as a result of nitrite reduction with hemoglobin. They can also react with some amines or amides present in the stomach forming $\mathrm{N}$ nitroso compounds with carcinogenic action. These are the reasons why, the nitrite content in food industry must be controlled and their determination must be currently done for checking the quality of meat products.

\section{Conclusion}

The results of the present study show that electrodes having $[\mathrm{MnL}](\mathrm{ac})_{2}$ as ionophore in onitrophenyloctylether plasticized polyvinyl chloride membranes, realized with an internal electric solid contact, exhibit a relatively high selectivity for nitrite over many anions. The most important characteristics of the electrodes having the optimum composition of the membrane are: slope: - $(59.8 \pm 0.1) \mathrm{mV} / \mathrm{dec}$ ade; linear range: $1.0 \times 10^{-6}-1.0 \times 10^{-1} \mathrm{M}$; detection limit: $5.0 \times 10^{-7} \mathrm{M}$; response time: $<10 \mathrm{~s}$.

\section{References}

[1] M.A. Marletta, A.Tayeh and J.M. Hevel, BioFactors, 2 (1990) 219.

[2] S. Archer, J. FASEB, 7 (1993) 349

[3] W. Lijinsky, S. S. Epstein Nature, 225 (1970) 21-23.

[4] E. Morcos, N.P. Wiklund, Electrophoresis, 22 (2001) 2763-2768.

[5] X. Yang, N. Kumar, H. Chi, D. B. Hibbert, P.W. Alexander Electroanalysis, 9 (1997) 549-553.

[6] M Shamsipur, M Yousefi, M Hosseini, M R Ganjali, Anal Lett:, 34 (2001) 2249-2261.

[7] M. Shamsipur, A. Avanes, M. Javanbakht, M. R.Ganjali, H. Sharghi, Anal Sci., 18 (2002) 875-879.

[8] M. R. Ganjali, M. Hosseini, F. Basiripour, M. Javanbakht, O. R. Hashemi, M. Rasteger Faal, M. Shamsipur, G. W. Buchanan Anal Chim Acta., 469 (2002) 181-186.

[9] M Shamsipur, M Javanbakht, V Lippolis, A Garau, M R Ganjali, A Yari, Anal Chim Acta 462 (2002) $225-234$

[10] M R Ganjali, M Yousefi, M Javanbakht, T Poursaberi, M Salavati-Niassari, L Hajiagha-Babaei, E Latifi, M Shamsipur, Anal Sci. 18 (2002) 887-892

[11] M Shamsipur, M Yousefi, M Hosseini, M R Ganjali, H Sharghi, H Naeimi, Anal Chem 73 (2001) $2869-2874$.

[12] M R Ganjali, T Poursaberi, L Hagi-agha Babaei, M Yousefi, S Rouhani, M Shamsipur, Fresenius, J Anal Chem , 370 (2001) $1091-$ 1095 .

[13] M Shamsipur, M Yousefi, M R Ganjali, Anal Chem, 72 (2000) 2344.

[14] S Kamata, A Bhale, Y Fukanaga, H Murata, Anal Chem, 60 (1988) 2464-2467.

[15] Y Umezawa, K Umezawa, H Sato, Pure Appl Chem, 67 (1995) 507-518.

[16] M. R. Ganjali, M. Rezapour, M. R. Pourjavid, M. Salavati-Niasari, Anal. Sci., 19 (2003) 1127-1131.

[17] M. R. Ganjali, S. Shirvani-Arani, P. Norouzi, M. Rezapour, M. Salavati-Niasari, Mikrochim. Acta., 146 (2004) $35-41$.

[18] M. Shamsipur, M. Javanbakht, A. R. Hassaninejad, H. Sharghi, M. R. Ganjali, M. F. Mousavi, Electroanalysis, 15 (2003) 12511259.

[19] W.P. Hu, X.Z. Dong, Z.J. He, Chin. J. Anal. Chem., 32 (2004) 765-768.

[20] A. Rawat, S. Chandra, A. Sarkar, Sensor Lett., 7 (2009) 1100-1105.

[21] Coordination Chemistry Reviews, 392 (2012) 438. 